\title{
A Study on the Design of Big Data Governance Framework in Higher Education and Its Application in Student Management
}

\author{
Ke Wang ${ }^{1}$ and Zhiyong Jiang ${ }^{1, *}$ \\ ${ }^{1}$ School of English, Beijing International Studies University, Beijing,100024, China \\ *Corresponding author. Email: jiangzhiyong@bisu.edu.cn
}

\begin{abstract}
Big data governance framework helps to analyze the logical structure of data governance and provides support for the implementation of data governance. The school-based education big data governance can solve the current problem of lack of education big data practice. Based on the practice dilemma of big data in university education, this paper has designed a reference framework for big data governance in university education, so as to help users analyze and settle the problems in the field of educational data governance in student management more comprehensively and objectively.
\end{abstract}

Keywords: Big Data in Education, Framework Design, Student Management

\section{INTRODUCTION}

With the in-depth advancement of education informatization, the Education Sector has fully recognized the significance of big data in education, and has explored data application standards, data quality and other related aspects, which has played a role in promoting data management and practical application in universities. Literature shows that big data research in China's education mainly focuses on the transformative role of big data exerted on education. Therefore, the research on education data governance is relatively limited. Consequently, the study and enforcement of big data governance is not only an inherent need for universities, but a force leading big data in education into practice as well as promoting the development of education modernization.

\section{STATUS QUO OF DATA GOVERNANCE}

The advent of the era of big data has brought new challenges and opportunities for the management and application of big data in education, which is followed by the significant data governance. Compared with data governance, big data governance places more emphasis on the comprehensive application value of data and related privacy protection. With the construction of digital campus and smart campus, education-related data become more and more sophisticated, the same is true of the data collection and storage, showing a much more obvious shape of big data. Big data in education has outstanding advantages in changing teaching methods, improving education quality and management efficiency, and innovating education governance. The education authorities have attached great importance to the application of big data in education, and have introduced policies to regulate the management and utilization of big data in education, laying the foundation for conducting big data governance in education.[1].

\section{PROBLEMS WITH DATA QUALITY}

A massive amount of mobile data is indispensable in the application of big data. After years of information construction, domestic universities have invested substantial funds to build various information systems and equipment covering business management and development of universities. At the same time, they have collected and stored a mass of data. There is, however, no effective convergence, sharing and utilization of these data, mainly for reason that no governance framework conforming to the real situation of universities is available. The following problems still exist nowadays.

\subsection{The Incapability of Data Sharing}

It is difficult to share data since there is no unified planning and standards at the school level. The construction of early information system was to be oriented towards the business functions with the underlying data structure design confusing and the storage form different, generating a variety of chaotic source data. The promotion of informatization in colleges and universities mainly relies on information centers. Although many institutions have set up groups such as information construction leading groups for decades and facilitate the development of information technology in schools by means of information centers, it has not changed the weak position of information centers. Whenever the data is to be shared, it 
would always be delayed or resisted by other departments, which makes the originally real-time data sharing stuck in a state of lag.[2].

\subsection{The Irregularity of Data's Quality}

The quality of data varies. During the construction and operation of early business systems, there were a quantity of problems, for example, non-standardized software design, unreasonable data structure design and nonverification of key data. Many systems were self-built by various departments who basically manage data according to their current business. Business systems that require multi-departmental collaboration with each other have poor collaboration mechanisms, resulting in quality problems like data duplication and data conflicts. Thus, data is not shared.

\subsection{The Disorder of Data Management Authority}

Situations like disorder of data management authority, unclear coordination mechanism within the school, and non-uniform data management authority system also occur. The maintenance of data is scattered in different departments, and permissions on the modification, sharing, and disclosure of data are disordered. Besides, the poor data linkage and common occurrence of data quality and data security problems have rendered trouble for relevant business which cannot receive support of data's update in a timely manner as required, let alone sustain the real-time scientific decision-making of schools

\subsection{The Deficiency of Data Lifecycle Management}

Data lifecycle management, which contains multiple stages including collection, production, storage, conversion, and application, is missing. In response to this phenomenon, whereas most of the managers of business systems are nonprofessional technical personnel who possess inferior information capability, weak awareness of data lifecycle management, and want of knowledge of the processes and systems in management. A large amount of historically retained cold data cannot be effectively identified and processed. All of this increases the difficulty and cost of data processing and weakens users' ability in data cognition, analysis, and application.

\subsection{The Blank of Supervision of Data Application}

There are regulatory gaps likewise in data application that bring issues of privacy protection and data security. In the whole life cycle of data, both the technical means as encryption, desensitization, log tracking and data auditing, and the legal and standardized daily use management are needed. Moreover, for a long time, not enough attention has been paid to the protection of students' privacy. Sensitive information as numbers of students' ID, that of mobile phone and bank cards are often unconsciously disclosed. Therefore, the lack of evidence on how to deal with privacy protection has caused a certain degree of trouble for the development of big data in education.

\subsection{The Insufficiency of Application of Data Innovation}

The innovative application of data is an inevitable process to realize the value of data. Information systems built in the early days did not support data interfaces that could be accessed, and it was difficult to extract data. Even though some information systems provided corresponding functions, they were comparatively simple and could not meet the needs of data openness. The exploitation of rich open interfaces of data involves not only technical factors, but institutional elements of data privacy, its security, and economic factors, which to a certain extent affect the development of innovation services of data. In spite of the fact that many a college have opened data service application interfaces, the scope and degree of openness are restricted, and there is no environment and atmosphere for teachers, students, and social forces to participate in the innovation of big data services in education.

\section{DESIGN OF FRAMEWORK FOR THE GOVERNANCE OF BIG DATA IN HIGHER EDUCATION}

In order to overcome the current dilemma of data, big data governance in university education should not only be supported from the technical environment and guaranteed from the institutional one, but needs to be dealt with according to the actual situation of the school by combining the data status and development goals of the institutions. This paper proposes a new reference framework for big data governance in education aiming at achieving innovative data applications and avoiding data risks. In addition, standards and policies and new organizational structures are to be formulated to assist the completion.

An important function of data governance is to establish a system of standards. Abiding by the interrelated standards can make the processing of data transactions achieve uniformity and standardization, ensure the consistency and readability of the meaning of data, and improve the effectiveness of data sharing. According to the whole life cycle management of data, the characteristics of the standards of data itself and its future development trends include basic standards, data standards, technical standards, etc. 
The organizational structure defines the organizational structure and responsibilities responsible for data matters, and a stable organizational structure and clear delineation of responsibilities is a guarantee for which the data governance be carried out effectively. A formal organizational structure is usually promulgated through a document issued by the university. In contrast, the informal one is formed spontaneously by university business departments and information centers in accordance with the requirements of process of business data without clear planning. The responsibilities among the departments involved are vague and unstable, which may lead to interruption of business if personnel adjustment occurs.

The data policy is a concrete measure for the achievement of the data strategy objectives, it contains the definition of data sources and data types, as well as the principles of data governance, guiding and regulating the implementation of data governance projects. Depending on the needs of the data strategy objectives, the data policy can be long-term or phased. The process for access to students' personal information is, firstly, the required data items and illustration of their use should be submitted by the requesting department, then the items ought to be reviewed and approved by the competent department and information center respectively, lastly, the data manager grants the requesting department's access to the data for a certain period.

The technology platform is located at the bottom of the system framework, it also serves as the basic support for data policy. With the expansion of the connotation and extension of big data, the traditional data technology system needs to be rapidly upgraded to one that capable of supporting big data management, processing, and application. The big data technology system should consist of big data acquisition technology, distributed big data processing technology, big data application and services, and other aspects. Universities is required to combine their existing technology systems and development goals, at the same time select suitable big data platform providers for the purpose of establishing a data service technology platform that can support the whole life cycle of data.

\section{IMPLEMENTATION STRATEGIES FOR BIG DATA GOVERNANCE IN HIGHER EDUCATION}

Big data in education is a process of gradual accumulation, which cannot solely be achieved by the construction of a big data management platform. The effectuation of data governance is a complex, iterative and spiralling course. Corresponding strategies are expected to speed up the smooth implementation of data governance and the achievement of its goals.

\subsection{Raise Data Awareness and Establish Data Thinking}

How to promote the healthy and orderly development of big data has become a hot spot of concern for education informatization nowadays. The understanding of big data cannot simply stay at the level of data processing and application, it should extend to having the data awareness and thinking. This requires leaders and administrators of universities to consider data from the source of thought, to acquire and cultivate the consciousness of speaking with data, employ data-driven mind in decision-making, management, and service, and abandon the mindset of relying on intuition and experience in the past. In consequence, creating an atmosphere of solving problems in the whole university by means of data.

\subsection{Strengthen the Status of Informatization and Policy Support}

The accuracy of information services is the immediate demand of the students when it comes to their own business. As China reaches a further development in education informatization, informatization occupies an increasingly important position in education and teaching. In the organizational structure of colleges and universities, therefore, the status of informatization department should be upgraded, the organizational structure of big data development be set up, and the responsibilities of departments and personnel be clarified. It is also necessary to strengthen the policy support, and make sure the information system construction centralize expenditure and management. Furthermore, the colleges may set up specific funds for informatization construction. The information systems that need to be built by each department ought to be controlled from the source by the information center which organizes experts to demonstrate, approve and accept.

\subsection{Enhance the Construction of Informatization Personnel}

As a brand-new industry, big data requires professional ability and quality of talents. It is essential to lay emphasis on both the introduction of professional talents and cultivation and motivation of existing personnel. This work is composed of reinforcing the capacity of professionals in the informatization department, attaching importance to the training of personnel who undertake informatization work in various departments, bringing into play the collaborative innovation ability of faculty, staff, and students, and encouraging collaborative innovation among faculty, students, and social forces. 


\subsection{Plan for Data Strategy Goals}

There is the necessity to plan for data strategy goals and implement these in a multi-phase and gradual way. The characteristics of big data regulate that the value and risk of data are difficult to assess quantitatively. Accordingly, data strategy goals should be focused on its achievability, with multi-stage goals and step-by-step implementation. They are based on the current situation of data and the data needs of stakeholder groups like faculty, administrators, and students. The data needs of the user groups are both the driver of data governance and the basis for assessing the achievement of goals.

\subsection{Advance Governance with Effectiveness}

Data governance is a complicated program that demands massive investment in terms of human and financial resources and continuous improvement. Too often, excessive investment without significant results at the school leadership or at the authority level leads to disruptions in governance. On account of this, universities may select business departments with a strong awareness of informatization, use small local data projects as entry points to address the pain points of business departments in management and services, such as student epidemic control data. They should optimize their business processes, improve management efficiency and service capacity, stimulate internal demand of business subjects, and gradually advance it from point to an area.

\subsection{Design Data Sharing and Quality Control Mechanisms in Advance}

The construction of previous information systems was in most cases business-oriented and lacked cognition in data sharing and control in procurement, construction, and operation, resulting in data disorder and data conflicts in the integration procedure in schools at a later stage, which often consumed a lot of resources for data cleaning, conversion, and integration. It is an essential prerequisite for the schools to design data sharing and quality control mechanisms in advance, make clear requirements in the procurement plan, and build the system strictly according to the former plan. In the implementation and operation stage, the information center should monitor data flow and data quality in real time and provide timely feedback on data problems, so as to realize the consistency between business systems and data centers.

\section{CONCLUSION}

Big data governance in education is capable of projecting, guiding, and supervising the definition, generation and use of data from the school's strategic targets, providing a theoretical basis and practical path for solving the dilemmas faced by big data in university education, promoting big data in university education towards practice, boosting data value realization and risk management, and enhancing data service capabilities. This paper has put forward a reference framework for big data governance in higher education, as well as implementation strategies for data governance, which can help universities and researchers analyze and solve problems in the field of education data governance in a more comprehensive and objective manner.

\section{ACKNOWLEDGMENT}

This work was supported by the 2020 Key Project of Party Construction and Ideological and Political Work of The Propaganda Department of the Party Committee of Beijing International Studies University -- Research on the Governance Framework design of Big Data in University Education and its application in Student Management (11171053)

\section{REFERENCES}

[1] Jiang Dongxing, Fu Xiaolong et al. "Discussion on the Construction of Wisdom Campus in Universities Under the Background of Big Data." Journal of East China Normal University (Natural Science Edition), S1, 2015, pp.119-125.

[2] Pei Ying, Fu Shiqiu et al. "Visualization Analysis of Hot Topics in Big Educational Data Research and Existing Problems." Distance Education in China, vol, 12, 2017, pp. 46-53.

[3] Wang Yongyan. "On Modern Construction and Path Choice of Education Governance Capacity in the Age of Big Data.” E-education Research, vol.8, no.38, 2017, pp.44-49.

[4] Wei Dajiang. A preliminary exploration of big data applications for student growth [R]. Nanjing: Beijing Xijia Chuangzhi Education Technology Co.,2017.

[5] Xu Xiaodong, Wang, Jinhua et al. "Data Governance in the Higher Education." Research in Higher Education of Engineering, vol.5, 2015, pp. 25-30.

[6] Yang Xianmin, Wang Duhui et al. "Application Models and Policy Recommendations of Big Data in Education. E-education research, vol.9, no.36, 2015, pp. 54-61.

[7] Yu Peng, Li Yan. "Research on University Data Governance Under the Perspective of Big Data." 
Modern Educational Technology, vol.6, no.28, 2018, pp. 61-67.

[8] Zhang Shaohua, Pan Rong et al. Big Data Governance and Services. Shanghai: Shanghai Science and Technology Press, 2016.
[9] Zheng Daqing, Huang Lihua et al. "Concept and Reference Architecture of Big Data Governance." Research and Development Management, vol.4, no.29, 2017, pp. 65-72. 